\title{
Period Effect
}

National Cancer Institute

\section{Source}

National Cancer Institute. Period Effect. NCI Thesaurus. Code C142633.

A change which occurs at a particular time, affecting all age groups and cohorts uniformly. 